\title{
Erratum to: The significance of transparent exopolymeric particles in the vertical distribution of bacteria and heterotrophic nanoflagellates in Lake Pavin
}

Mohamad-Bashir Arnous - Nicolas Courcol • Jean-François Carrias

Published online: 25 March 2010

(C) Springer Basel AG 2010

Erratum to: Aquat Sci (2010) 72:245-253

DOI 10.1007/s00027-010-0127-x

The correct units in Fig. 1 are particles $\times 10^{6} \mathrm{~L}^{-1}$ (instead of particles $\times 10^{5} \mathrm{~L}^{-1}$ ).

The online version of the original article can be found under doi:10.1007/s00027-010-0127-x.

M.-B. Arnous · N. Courcol · J.-F. Carrias

Clermont Université, Université Blaise Pascal, BP 10448,

63000 Clermont-Ferrand, France

M.-B. Arnous · N. Courcol · J.-F. Carrias ( $₫)$

Laboratoire Microorganismes: Génome et Environnement

(LMGE), UMR CNRS, 6023, 63177 Aubière, France

e-mail: j-francois.carrias@univ-bpclermont.fr 